\title{
The Effect of a Task-oriented Upper Arm Exercise on Stable and Unstable Surfaces on Dynamic Balance and Hand Function in Patient with Cerebral Palsy
}

\author{
Yong-Gu Han', Chang-Kyo Yun ${ }^{2}$ \\ 'Daegu University Rehabilitation Clinic, Daegu; ${ }^{2}$ Department of Physical therapy, College of Rehabilitation Science, Graduate School, Daegu \\ University, Daegu, Korea
}

Purpose: The purpose of this study was to investigate the effects of a task-oriented upper arm exercise performed in a sitting position on either an unstable support surface or a stable support surface for children with cerebral palsy.

Methods: We prospectively evaluated 18 children with cerebral palsy. Eight subjects were randomly assigned to each of the stable and unstable support surface groups. We performed the upper arm exercise three times a week for 6 weeks. To confirm the effects of the intervention, the berg balance scale test, modified functional reaching test (MFRT), timed up and go test (TUG), and Jebsen-Taylor hand function test were conducted before and after the study.

Results: Significant differences were observed in MFRT and TUG between the experimental and control groups $(p<0.05)$. In the JebsenTaylor hand function test, there were significant differences between the groups for the items picking up small objects, stacking checkers, lifting large light objects, and lifting large heavy objects $(p<0.05)$, but not for writing and stimulation of feeding. Significant differences were observed between the groups in items of card turning, lifting large light objects, and lifting heavy objects.

Conclusion: The purpose of this study was to evaluate the effectiveness of a task-oriented upper extremity exercise program for dynamic balance and hand function performed in a sitting position with either stable or unstable support by cerebral palsy patients. There were improvements in the two groups, but performing the exercise while sitting on an unstable support surface had a greater effect on dynamic balance and hand function than exercise while sitting on a stable supporting surface. The results of this study can be used to improve the daily lives of cerebral palsy patients.

Keywords: Cerebral palsy, Unstable, Stable, Task-oriented approach, Upper extremity exercise

\section{서 론}

뇌성마비는 발달중인 태아나 유아에 발생하는 비진행성 뇌병변으로 인해 움직임이나 자세의 발달에 장애를 가지는 질환이 아닌 임상적 특징이 유사한 증후군을 의미한다.' 이러한 미성숙한 뇌의 발달로 인 하여 근 골격계와 신경계의 발달이 완전하지 못하며, 비정상적인 근 긴장도, 근력 약화, 운동 실조, 협응 장애 등의 문제가 나타나게 된다. ${ }^{2}$ 뇌성마비의 발생 요인으로는 선천성 기형, 감염, 조산, 혈액형 부적합 성, 발육 지연 등이 있고, 위험 요소로는 출산 시 난산으로 인한 출혈 과 산소 결핍, 기계적인 분만 등이 있다. 이와 같은 발생 요인으로 인 하여 출생 후 뇌성마비 아동들은 비정상적인 발달과정을 경험하고
평형감각, 원시반사의 부적절한 조절능력의 결과로 일상생활동작에 기능적인 문제가 생기게 된다. ${ }^{4}$

일상적인 과제 수행 시 뇌성마비 아동은 관절가동범위가 충분하 지 않기 때문에 보상적인 움직임을 사용하게 되어 정상적인 팔 기능 을 수행할 수 없게 되고, ${ }^{5}$ 특히 사지마비나 편마비 아동의 경우 '학습 화 비사용으로 인해 비우세 측 팔을 사용하지 않게 되는 경향이 두드 러져 우세 측 팔 만을 사용해서 부족한 움직임을 보상하는 방법을 배운다. ${ }^{6}$ 일반적으로 팔 기능의 회복은 다리기능의 회복보다 더딘 경 우가 많으며 ${ }^{7}$ 이러한 습관화된 패턴으로 인해 비우세 측 팔이 회복됨 에도 불구하고 더 이상 사용하지 않으려는 경향을 보이게 된다.89

팔 기능을 회복하기 위한 방법으로 과제지향적 접근방식은 최근
Received Feb 19, 2017 Revised Mar 31, 2017

Accepted Apr 7, 2017

Corresponding author Chang-Kyo Yun

E-mail puhaha1116@naver.com
Copylight (C) 2017 The Korea Society of Physical Therapy

This is an Open Access article distribute under the terms of the Creative Commons Attribution Non-commercial License (Http:// creativecommons.org/license/by-nc/4.0.) which permits unrestricted non-commercial use, distribution, and reproduction in any medium, provided the original work is properly cited. 
신경학적 손상을 입은 환자들을 대상으로 사용되고 있는 새로운 접 근법이며, 운동 발달과 학습에 효과적인 중재 방법이다. ${ }^{10}$ 뇌성마비, 뇌졸중 등 많은 환자들에게 적용되고 있으며 뇌 가소성을 일으키는 데 효율적이고 재활 치료 분야에서 환자들의 팔 기능의 개선을 위해 널리 사용되는 방법이다.10,11

더 나아가 최근에는 우세 측 팔을 제한하고 과제지향적 접근방법 을 사용하는 치료법이 사용되고 있다.12 constraint-induced movement therapy (CIMT)라 명칭 하는 중재방법으로 이와 관련된 최근의 선행 연구를 살펴보면 편 측 마비 아동을 대상으로 우세 측 팔을 제한해 서 수정된 우세 측 팔 운동 제한 치료를 적용한 결과 비 우세측 팔의 운동 및 감각기능이 향상되었고, 일상생활에서 비우세 측 팔의 사용 빈도가 증대 되었으며 1 개월 동안 치료 효과가 유지된 결과가 보고되 었다. ${ }^{13}$

이에 더해서 최근에 신경계 손상 환자를 대상으로 한 불안정한 지 지면에서의 훈련이 보고 되고 있다. 뇌졸중 환자를 대상으로 불안정 한 지지면에서 이중과제 훈련을 했을 때와 안정적인 지지면에서 시행 했을 때를 비교 했을 때 불안정한 지지면에서의 훈련이 정적, 동적 균 형 능력의 개선에 더 효과적이었다. ${ }^{14}$

위의 연구들을 살펴보면 과제지향적 접근방법이 신경학적 손상을 입은 환자들에게 효율적인 중재방법이고, 불안정한 지지면에서의 과 제 훈련이 안정적인 지지면에서의 훈련 보다 더 효과적이라는 점을 시사한다. 하지만 뇌졸중 환자를 대상으로 과제지향적 중재를 적용 한 사례에 비해 뇌성마비 아동을 대상으로 시행한 연구는 부족하다. 또한 뇌성마비 환자를 대상으로 불안정한 지지면에서 비 우세 측 팔 에 선택적으로 과제지향적 중재를 적용한 사례도 많지 않다. 신경학 적 손상이 원인이라는 점에서는 유사점이 있지만 뇌졸중 환자와 뇌 성마비 환자의 특징은 다르기 때문에 뇌졸중 환자를 대상으로 효과 적인 중재 방법이 뇌성마비 환자에게도 비슷하게 적용되는지 알아 볼 필요가 있다. 따라서 본 연구에서는 뇌성마비 아동을 대상으로 불 안정한 지지면에서 비우세 측 팔에 과제지향적 팔 운동프로그램을 적용했을 때 안정적인 지지면에서 시행했을 때 보다 비우세 측 팔 기 능과 균형 능력의 향상에 얼마나 더 효과적인지 알아보고자 한다.

\section{연구 방법}

\section{1. 연구대상}

본 연구는 D 광역시 D 의원에서 물리, 작업 재활치료를 받고 있는 뇌 성마비 아동 18 명을 대상자로 선정하였고 보호자에게 전원 동의를 받았다. 아동은 지시 수행이 가능하고 뇌성마비 대운동 기능 분류 시 스템(gross motor function classification system, GMFCS) 평가에서 3단 계 이상이며 불안정한 바닥면 위에서 독립적인 앉기와 체중부하자
세 유지가 가능한 아동으로 하였다. 대상자는 9명씩 실험군(experimental group)과 대조군(control group)에 제비뽑기를 통해 무작위로 배치하였다. 대조군은 편평한 바닥면에서 앉은 자세로 상지운동 프 로그램을 적용하였고, 실험군은 균형판 위에 앉아서 같은 프로그램 을 수행하였다. 실험기간은 2016년 12월 12일부터 2017년 1월 20일까 지 진행하였다.

추가적인 대상자 조건은 아래와같도록 선정하였다.

1) 뇌성마비로 진단을 받은 환자

2) 5 분 이상 독립적인 앉기가 가능한 환자

3) 시각, 청각의 결손 및 장애가 없는 환자

4) 지시를 듣고 수행할 만큼 의사소통이 가능한 수준의 인지를 가 진환자

5) 부모로부터 연구 참가 동의를 받은 환자

\section{2. 실험방법}

1) 측정도구

(1) 팔 운동 프로그램

본 연구의 중재 운동 프로그램은 뇌졸중 환자를 대상으로 실시한 $\mathrm{Jung}^{15}$ 의 과제지향적 팔 운동 프로그램을 아동에 맞게 수정 보완 하 여 실시하였다. Jung J $^{5}$ 의 과제는 (1)스위치 누르기 1-1(시작 스위치와 종료 스위치가 $30 \mathrm{~cm}$ 간격으로 놓여 있는 스위치를 팔을 뻗어 손바닥 으로 누르는 과제, (2)스위치 누르기 1-2(일정 거리에 놓은 5개의 스위 치를 팔을 뻗어 손바닥으로 누르는 과제, (3)스위치 누르기 1-3(앉은 자세에서 상, 하, 좌, 우의 위치에 있는 목표물에 팔을 뻗어 손바닥으 로 스위치를 누르는 과제, (4)플라스틱 병 옮기기(굵기, 높이, 무게가 다른 5 개의 플라스틱 병을 팔 뻗기-잡기-옮기기-놓기의 과제), (5)페그 보드에서 페그 빼서 넣기(앉은 자세에서 비우세 측 팔을 이용하여 직 경 $2.5 \mathrm{~cm}$, 높이 $12 \mathrm{~cm}$ 인 페그를 빼서 상자 위에 놓여진 바구니에 담는 과제, (6)구슬 옮기기 (직경이 각각 $1.2 \mathrm{~cm}$ 와 $0.6 \mathrm{~cm}$ 인 두 종류의 구슬 각각 20 개를 옮기는 과제)로 구성되어 있다. 실험군 아동은 등받이가 있는 의자 위에 밸런스 보드를 깔고 앉아서 엉덩관절, 무릎관절, 발목 관절을 90 도로 굽히고 발바닥이 바닥에 닿는 자세로 수행했고, 대조 군 아동은 같은 조건을 편평한 의자 위에서 시행하였다. 중재를 위한 도구는 치료실 내에서 구할 수 있는 물품들을 대상으로 선정했다. 중 재는 편 측 마비 아동의 경우 마비 측에, 양하지 마비 아동의 경우 비 우세 측 팔에 적용했다. 기존 연구에서 사용한 스위치를 아동들의 흥 미 유발을 유도하기 위해 스티커 자석을 누르는 것으로 수정 했으며 치료실에서 일반적으로 구하기 힘든 벽면 스위치를 이용한 과제인 과 제 5 를 삭제하였다. 스티커 자석 5 개를 누르는 과제 2 는 중재자가 옆에 서 순서를 무작위로 바꾸면서 지시하도록 유도했고 과제를 수행하기 전에 준비 운동으로 5 분 동안 충분한 수동 관절가동범위 운동을 시 

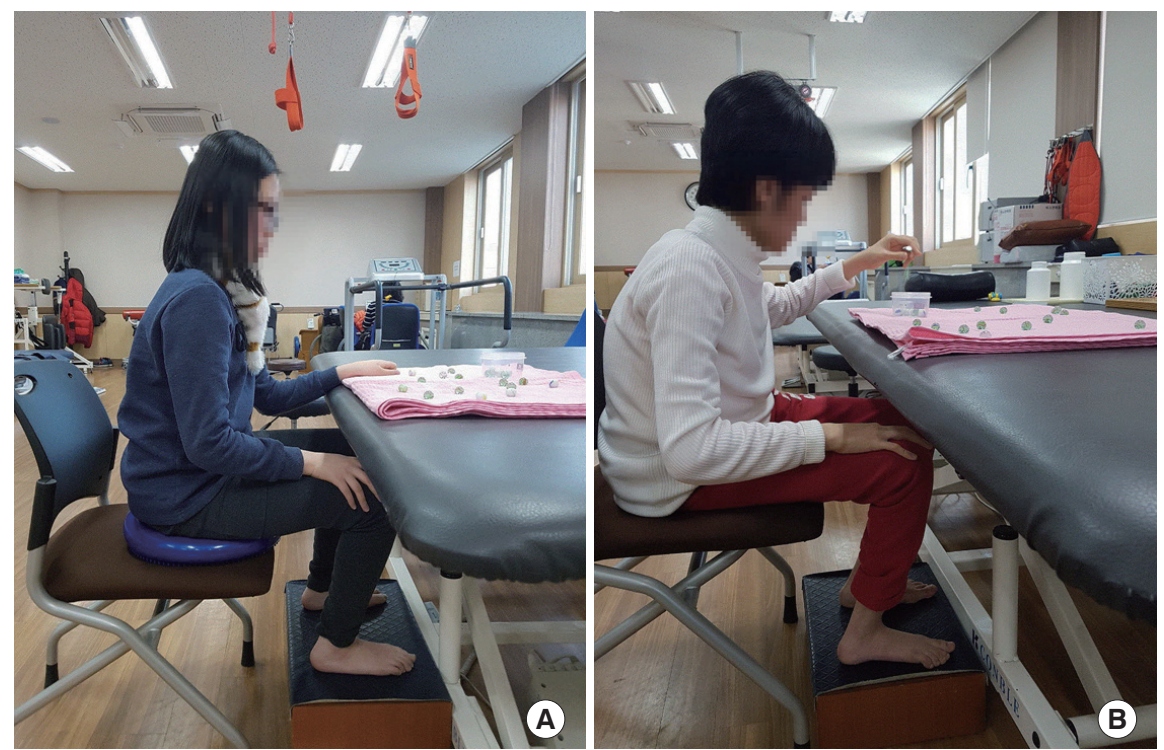

Figure 1. The picture of exercise shows how to sit on an unstable support surface and a stable support surface to execute the marble movement task. Left picture is experimental group $(A)$ - sitting on unstable surface.

Right picture is control group (B) - sitting on stable surface.

Table 1. General characteristics of subjects $(n=18)$

\begin{tabular}{lccc}
\hline Measurement & EG & CG $(n=9)$ & Total $(n=18)$ \\
\hline Age (year) & $13.78 \pm 2.91$ & $14.33 \pm 1.58$ & $14.06 \pm 2.29$ \\
Gender (male/female) & $5 / 4$ & $5 / 4$ & $10 / 8$ \\
Height $(\mathrm{cm})$ & $153.39 \pm 16.46$ & $157.86 \pm 10.08$ & $155.62 \pm 13.44$ \\
Weight $(\mathrm{kg})$ & $46.74 \pm 13.03$ & $50.80 \pm 9.70$ & $48.77 \pm 11.34$ \\
GMFCS $(\mathrm{I} / \mathrm{II} / \mathrm{III})$ & $2004-03-02$ & $2001-07-01$ & $2005-10-03$ \\
\hline
\end{tabular}

EG: experimental group, CG: control group. ${ }^{*} p<0.05$.

행하였다. 준비운동을 포함하여 각 과제는 5 분씩 총 30 분 동안 진행 되었다(Figure 1).

\section{(2) 평가도구}

(1) Jebsen-Taylor hand function test

본 연구의 운동 프로그램은 선행연구 15 에 따라 비 우세측 팔에 적용 했 기 때문에 평가 결과도 비우세 측 팔에 한정해서 측정하였다. 7 개의 과제 로 구성되어 있으며 각 항목마다 3 번씩 측정하여 평균값을 기록하였다.

\section{(2) Modified fuctional reaching test}

수정된 기능적 뻗기 검사는 서서 기능적 뻗기를 할 수 없는 급성기 환 자를 대상으로 만들어진 측정 방법이다. 본 연구의 환자들은 GMFCS 단계가 1-3단계까지 다양하고 3단계 아동의 경우 서서 동적 균형 검사를 수행하기 어렵기 때문에 본 연구에서는 수정된 기능적 뻗기 검사를 사용하였다. 대상자는 등받이가 있는 의자에 엉덩관절, 무릎 관절, 발목관절을 90 도로 굽힌 상태로 앉고 팔을 90 도로 굽힌다. 이
Table 2. Dynamic balance

\begin{tabular}{|c|c|c|c|c|c|}
\hline & \multirow[t]{2}{*}{ Group } & \multirow[t]{2}{*}{ Pre } & \multirow[t]{2}{*}{ Post } & $\begin{array}{l}\text { Within } \\
\text { group }\end{array}$ & \multirow{2}{*}{$\begin{array}{c}\text { Between } \\
\text { group }\end{array}$} \\
\hline & & & & $p$ & \\
\hline \multirow[t]{2}{*}{ MFRT } & $\mathrm{EG}$ & $16.53 \pm 5.98$ & $20.30 \pm 7.08$ & $0.00^{*}$ & $0.03^{*}$ \\
\hline & CG & $26.17 \pm 12.60$ & $29.00 \pm 13.20$ & $0.00^{*}$ & \\
\hline \multirow[t]{2}{*}{ TUG } & EG & $11.41 \pm 4.23$ & $9.24 \pm 2.90$ & $0.00^{*}$ & $0.01^{*}$ \\
\hline & CG & $11.22 \pm 2.82$ & $10.50 \pm 2.91$ & $0.02^{*}$ & \\
\hline
\end{tabular}

EG: experimental group, $\mathrm{CG}$ : control group ${ }^{*} p<0.05$

때 손가락 끝의 지점을 기록하고 최대한 앞쪽으로 기울여 넘어지지 않을 만큼까지 팔을 앞으로 뻗게 하여 이때의 거리를 측정하였다. 팔 을 뻗은 상태에서 측정한 값에서 시작 자세에서 측정한 값을 뺀 값을 평가 점수로 이용하였다. 이 검사법은 BBS와 TUG와 상관관계가 증 명된 측정 방법이며 측정이 쉽기 때문에 임상에서 자주 이용된다.16

(3) Timed up and go test (TUG)

환자에게 의자에서 일어나서 $3 \mathrm{~m}$ 보행을 하고 방향을 전환하여 되돌 아오는 시간을 기록했다. TUG는 중재 전 후 세 번씩 측정해서 평균값 으로 평가하였다.

\section{3. 자료 분석}

수집된 자료는 SPSS for Windows version 14.0을 이용하여 통계처리 하 였다. 기술 통계를 통하여 평균 표준편차를 구했고, 정규성 검정을 만 족하여 군내 통계는 paired-T test, 군 간 통계는 independent T-test를 이 용하여 측정하였다. 
Table 3. Jebsen-Taylor hand function test

\begin{tabular}{|c|c|c|c|c|c|}
\hline & \multirow{2}{*}{ Group } & \multirow{2}{*}{ Pre } & \multirow{2}{*}{ Post } & Within group & \multirow{2}{*}{$\frac{\text { Between group }}{\mathrm{p}}$} \\
\hline & & & & $\mathrm{p}$ & \\
\hline \multirow[t]{2}{*}{ Writing } & EG & $56.05 \pm 23.97$ & $59.39 \pm 29.84$ & 0.53 & 0.32 \\
\hline & CG & $42.33 \pm 17.06$ & $40.13 \pm 15.25$ & 0.232 & \\
\hline \multirow[t]{2}{*}{ Card turning } & EG & $11.01 \pm 2.61$ & $7.32 \pm 1.52$ & $0.001^{*}$ & 0.03 \\
\hline & CG & $13.81 \pm 6.24$ & $12.26 \pm 6.59$ & $0.006^{*}$ & \\
\hline \multirow[t]{2}{*}{ Picking up small object } & EG & $8.31 \pm 1.46$ & $5.02 \pm 2.20$ & $0.000^{*}$ & 0.16 \\
\hline & CG & $12.89 \pm 6.27$ & $7.58 \pm 4.87$ & $0.004^{*}$ & \\
\hline \multirow[t]{2}{*}{ Simulation on feeding } & EG & $32.89 \pm 6.81$ & $30.07 \pm 10.34$ & 0.259 & 0.51 \\
\hline & CG & $20.35 \pm 5.64$ & $19.22 \pm 6.41$ & 0.198 & \\
\hline \multirow[t]{2}{*}{ Stacking checkers } & EG & $11.90 \pm 3.19$ & $7.06 \pm 1.63$ & $0.000^{*}$ & 0.60 \\
\hline & CG & $13.72 \pm 5.86$ & $9.66 \pm 4.19$ & $0.012^{*}$ & \\
\hline \multirow[t]{2}{*}{ Lifting large Light objects } & EG & $9.48 \pm 1.68$ & $5.06 \pm 0.39$ & $0.000^{*}$ & 0.002 \\
\hline & CG & $8.88 \pm 4.02$ & $7.06 \pm 4.35$ & $0.002^{*}$ & \\
\hline \multirow[t]{2}{*}{ Lifting large heavy objects } & EG & $10.66 \pm 2.23$ & $5.10 \pm 0.78$ & $0.000^{*}$ & $0.001^{*}$ \\
\hline & CG & $10.38 \pm 5.07$ & $8.22 \pm 4.48$ & $0.002^{*}$ & \\
\hline
\end{tabular}

EG: experimental group, CG: control group

${ }^{*} \mathrm{p}<0.05$.

\section{결 과}

\section{1. 연구 대상자의 일반적 특성}

본 실험의 연구 대상자는 총 18 명으로 남자 10 명, 여자 8 명이 참여하 였고, 연령은 9-12세 6명, 13-17세 12명으로 구성되었다. 뇌성마비의 종 류는 양하지 마비 환아가 10 명, 편측 마비 환아가 6 명, 실조성 아동 1 명, 사지마비 1 명이었다. 대상자의 GMFCS 단계는 1단계가 5명, 2단계 가 10 명, 3 단계가 3 명이었다. 그룹 선정은 실험군과 대조군에 제비뽑 기를 통해 무작위로 배정되었다(Table 1).

\section{MFRT, TUG, Jebsen-Talyer hand function 점수의 변화량 비교}

연구 대상자의 MFRT, TUG, Jebsen-Talyor hand function test의 측정값 은 Tables2, 3과 같다. MFRT와 TUG에서 그룹 내에서 실험군과 대조군 모두 유의한 차이가 관찰되었고 $(\mathrm{p}<0.05)$, 그룹 간 비교에서도 유의한 차이가 관찰되었다 $(\mathrm{p}<0.05)$ (Table 2). Jebsen-Taylor hand function test에 서는 writing 항목과 stimulation on feeding 항목을 제외한 나머지 picking up small object, stacking checkers, lifting large light objects, lifting large heavy objects 항목에서 그룹 내 유의한 차이를 보였다 $(\mathrm{p}<0.05)$. 또한 5 가지 항목 중에 card turning, lifting large light objects, lifting heavy objects 항목에서 그룹 간 유의한 차이가 관찰되었다(Table 3).

\section{고 찰}

본 연구는 뇌성마비 아동을 대상으로 불안정한 지지면에서 비우세 팔을 이용해서 과제지향적 팔 운동프로그램을 적용했을 때 균형 능
력과 팔 기능의 증진에 얼마나 효과적인지를 알아보고자 하였다. 실 험군은 밸런스 보드 위에 앉아서 과제지향적 팔 운동프로그램을 적 용했으며, 대조군은 편평한 바닥면 위에 앉아서 동일한 운동프로그 램을 시행하였다.

대뇌의 겉질 영역은 개별 근육의 조절을 위한 것이 아니라 특정 과 제를 수행하기 위해 설계되었다. ${ }^{17}$ 따라서 뇌의 활성화에 과제 특이적 운동이 목표가 없는 움직임보다 더 효과적으로 기여한다. ${ }^{18}$ 또한 국 소 뇌 손상 원숭이를 대상으로 비 우세 측 팔에 과제 훈련을 시행했 을 시 과제 수행 경험이 대뇌의 겉질 영역을 변화시킨다는 사실도 증 명되었다. ${ }^{19}$ 특히 손가락 영역의 $22 \%$ 를 손상시킨 후, 과제훈련을 수행 했을 때 여분의 손가락영역이 $15 \%$ 증가되었다. ${ }^{19}$ 과제지향적 훈련의 연구는 지속적으로 발전해 왔으며,,$^{20} \mathrm{Bosch}^{21}$ 의 연구에 의하면 집중적 인 과제훈련이 뇌 손상 환자의 겉질 영역의 재구성을 유발하였고, 과 제 수행을 위한 손 기능이 향상되었다. 또한 뇌졸중 환자를 대상으로 과제지향적 훈련과 통상적인 작업치료를 받은 그룹을 비교한 연구에 서 과제지향적 팔 운동프로그램을 적용한 대상자 군이 통상적인 작 업치료를 받은 그룹 보다 비우세 측 팔 기능에서 기능적으로 더 큰 개 선을 보였다.22 따라서 본 연구에서는 비우세 측 팔에 과제지향적 팔 운동프로그램을 적용 했고 실험군과 대조군 모두에서 Jebsen-Taylor hand function test의 대부분의 항목인 picking up small object, card turning, lifting large light objects, lifting heavy objects에서 개선이 있었 다. 이것은 기존의 연구와 일치하는 결과이며 과제지향적 팔 운동프 로그램이 뇌졸중 환자뿐만 아니라 뇌성마비 아동에게도 효율적인 운동프로그램임을 알 수 있다. 다만 뇌성마비 아동은 주의 집중, 기억 등의 인지 기능에 결함을 가지고 있으며, ${ }^{23}$ 이와 같은 뇌성마비 아동 
의 인지 수준에 비하여 writing과 stimulation on feeding은 과제의 높 은 난이도를 가지고 있어 중재에 따른 차이를 발견하지 못한 것으로 생각된다. 그리고 두 그룹 군 간의 차이에서 card tuning, lifting large light objects, lifting heavy objects의 3가지 항목에서 통계적으로 유의 한 차이가 관찰되었다. 정상인을 대상으로 불안정한 지지면과 안정적 인 지지면에 앉아서 덤벨 운동을 시행했을 때 근육의 활성도를 비교 한 선행 연구를 살펴보면, 불안정한 지지면에 앉아서 운동을 할 경우 몸 쪽 관절의 안정성이 떨어지게 되고 이를 보상하기 위해서 위팔 세 갈래근, 배 곧은근, 배 바깥 경사근의 근전도 반응이 상대적으로 더 활성화 된다는 결과를 보고하였다. ${ }^{24}$ 이러한 근육들은 어깨 관절과 척 추 관절의 안정성에 기여하는 근육들이다. 따라서 근육 활성도의 변 화가 어깨와 척추 관절의 안정성을 증대시키는 데 도움이 되었을 것이 고 몸 쪽 관절의 안정성의 증가가 실험군 환자의 팔 기능에 더 큰 변화 를 초래한 것으로 생각된다. 그리고 두 그룹 간의 차이에서 일부 항목 에서만 통계적으로 유의한 개선이 나타난 이유는 팔 기능에 대한 6주 간의 중재가 오랜 기간 동안 지속되어온 뇌성마비 환자의 팔 기능 결 함에서 손의 섬세함과 세밀함을 바꾸기에는 충분하지 않았으나, card tuning, lifting large light objects, lifting heavy objects 같은 크고 대 동작 중심의 측정에는 영향을 미쳤음을 알 수 있다. 실제로 큰 물체를 잡는 대 동작 위주의 과제 수행은 외재근이 주로 작용하며 작은 물체를 잡 는 동작은 손의 내재근이 작용하는데 내재근은 작은 관절 주변에 위 치하며 만성적인 손기능의 저하에 의한 근력 약화에 대해 외재근 보 다 더 큰 영향을 받는다. ${ }^{25}$ 하지만 본 연구에서 사용된 팔 운동프로그 램은 구슬 옮기기를 제외하고는 상대적으로 큰 도구를 잡는 과제가 많았기 때문에 내재근 보다는 외재근의 훈련 효과가 더 컸을 것으로 생각된다. 내재근의 훈련은 외재근의 훈련보다 더 오랜 시간이 소요되 며 ${ }^{25}$ 적은 과제의 수에 의하여 Jebsen-talyor hand function test에서 대 동작 위주의 측정에 더 큰 영향을 미쳤을 것으로 해석된다.

본 연구에서 일부 적용한 CIMT는 최초 원숭이 실험에서 기원을 둔 접근법이다. ${ }^{8} \mathrm{CIMT}$ 는 '학습화 비사용 이론'을 바탕으로 시작된 치 료 방법으로 우세 측 보다 비우세 측 팔을 사용하게 함으로써 비우세 측 팔의 기능 수행의 참여도를 증진 시키고 행동의 변화를 유도하는 방법이다. 실제로 원숭이의 한쪽 대뇌를 손상시킨 뒤 우세 측 팔을 강제로 묶어서 사용하지 못하게 만들고, 비우세 측 팔을 강제적으로 사용하도록 유도한 뒤 학습화 비사용을 극복할 수 있었다. ${ }^{8.9}$ 특정 부 위의 억제와 반복 기법은 인간을 대상으로 연구가 확대되었고 최근 에는 '억제유도 운동치료'라는 명칭으로 작업치료와 물리치료 전반 에 걸쳐 흔히 사용된다. ${ }^{26,27} \mathrm{CIMT}$ 는 높은 수준의 근거를 바탕으로 중 재의 효과성을 뒷받침하였고, ${ }^{28}$ 신뢰성을 인정받았다. ${ }^{26,29,30}$ 따라서 비 우세 측 팔을 강제적으로 사용하는 것이 학습화 비사용을 극복하고 부족한 비우세 측 팔 기능의 향상에 효과적인 중재 방법이며 본 연구
에서도 CIMT 기법의 비우세 측 팔의 훈련을 적용해서 중재 시 비우 세 측 팔에만 선택적으로 과제를 수행하였다.

더해서 본 연구에서는 불안정한 지지면을 사용하였다. 뇌성마비 아동은 비정상적인 발달 과정을 거치게 되고 균형 능력의 감소와 부 족한 몸통 안전성으로 인해 팔 기능이 떨어진다. ${ }^{31}$ 따라서 뇌 병변 아 동의 몸통 근육 강화는 매우 중요하며 이를 개선시키기 위해 많은 중 재 방법들이 사용되고 있다. 특히 복부의 안정성을 개선시키기 위해 서 불안정한 지지면에서의 운동이 대두되고 있다. ${ }^{32}$ 불안정한 지지면 에서의 운동은 안정적인 지지면에 비해 복부 근육의 활성도 변화에 더 효과적 25,33 이라는 선행 연구가 있으며 최근 연구에서도 불안정한 지지면에서의 운동은 체중이동에 대한 동적 반응을 촉진함으로써 효율적으로 몸통 근육을 활성화 한다는 결과가 보고 되었다. ${ }^{33,34}$ 또한 뇌성마비 아동을 대상으로 몸통과 목에 집중적인 안정화 운동을 적 용했을 때 Jebsen-Taylor hand function test와 K-DTVP-2 test에 유의한 차이를 보이는 연구가 보고되었다. ${ }^{35}$ 기존 뇌졸중 환자를 대상으로 시행한 연구에서도 불안정한 지지면에서 과제지향적 팔 운동프로그 램을 시행했을 때 안정적인 지지면에서 시행한 그룹보다 동적, 정적 균형 측정에서 유의한 차이를 보였고, ${ }^{36}$ 본 연구의 측정값을 살펴봐 도 안정적인 지지면 보다 불안정한 지지면에 앉아서 과제를 수행한 그룹이 동적 균형검사인 MFRT, TUG에서 통계적으로 더 큰 개선을 보였다. 따라서 본 연구에서 불안정한 지지면을 이용함으로써 몸통 근육의 동적 안정성에 더 큰 영향을 미쳤을 것이고 그룹 간 차이에서 통계적으로 유의한 차이가 관찰된 것으로 보인다.

결론적으로 보호자 및 치료사의 임상 적용에서 뇌성마비 환자의 팔 기능 치료 프로그램 적용 시 팔 기능과 동적 균형에 긍정적인 영향 을 주기 위해서 안정된 지지면 보다 불안정한 지지면을 제공하는 것 이 필요해 보인다.

연구의 제한 점으로는 임상적인 한계로 인해 많은 대상자를 모집 할수 없었다. 따라서 뇌성마비의 종류에 따른 분류를 하지 못했고 뇌 성마비의 분류 별로 중재가 얼마나 효과적인지는 알 수 없었다. 특히 비우세측 손에 대한 중재가 주요한 영향을 미칠 수 있는 편 측 마비 환자의 수가 적었고 대부분 양하지 마비 환자를 대상으로 중재가 실 시된 점이 제한 점으로 생각된다. 또한 GMFCS 1-2단계 위주로 대상 자를 모집하였기 때문에 기능 수준에 따른 치료 중재의 일반화도 어 려운 점 또한 제한 점으로 보인다. 더욱이 추적조사를 시행하지 못했 기 때문에 치료의 효과가 어느 정도 지속되는지도 알 수 없다. 마지막 으로 대 동작 위주의 과제가 많기 때문에 세심한 동작을 요구하는 과 제에 대한 훈련을 추가하여 중재의 효과성을 추가 입증할 필요가 있 을 것으로 생각된다. 따라서 대상자와 과제를 더욱 세분화 하고 제한 점에 대한 보완적인 연구가 진행 된다면 뇌성마비 환자의 팔 기능과 균형을 개선하기 위한 효율적인 중재프로그램을 완성하는데 도움이 
될 것으로 생각된다.

\section{결 론}

본 연구는 뇌성마비 환자를 대상으로 안정적인 지지면과 불안정한 지지면에 앉아서 비 우세측 팔에 과제지향적 팔 운동 프로그램을 시 행했을 때 동적 균형과 비 우세측 팔 기능에 얼마나 효과적인지 알아 보고자 하였다. 두 그룹 군 모두 개선이 있었지만 불안정한 지지면에 앉아서 중재를 수행했을 때 안정적인 지지면 앉아서 수행했을 때 보 다 동적 균형과 팔 기능에서 더 큰 효과가 있었다. 본 연구에서 시사 하는 바를 지역사회에서 환자를 위해 수행한다면 뇌성마비 환자들 에게 효과적인 중재 방법이 될 것으로 제언한다.

\section{참고문헌}

1. Shamsoddini A, Amirsalari S, Hollisaz MT et al. Management of spasticity in children with cerebral palsy. Iran J Pediatr. 2014;24(4):345-51.

2. Bass N. Cerebral palsy and neurodegenerative disease. Curr Opin Pediatr. 1999;11(6):504-7.

3. Braun KVN, Doernberg N, Schieve L et al. Birth prevalence of cerebral palsy: a population-based study. Pediatrics. 2016;137:1-9.

4. James S, Ziviani J, Boyd R. A systematic review of activities of daily living measures for children and adolescents with cerebral palsy. Dev Med Child Neurol. 2014;56(3):233-44.

5. Arnould C, Bleyenheuft Y, Thonnard J. Hand functioning in children with cerebral palsy. Front Neurol. 2014;5:48.

6. Taub E. Movement in nonhuman primates deprived of somatosensory feedback. Exerc Sports Sci Rev. 1976;4:335-74.

7. Sung IY, Park JM. A pilot evaluation of cast immobilization of intact upper extremity: a new therapeutic approach for spastic hemiplegic cerebral palsy. J Korean Acad Rehabil Med. 1998;22(4):828-32.

8. Taub E, Crago JE, Burgio T et al. An operant approach to rehabilitation medicine: overcoming learned non use by shaping. J Exp Anal Behav. 1994;61:281-93.

9. Taub E. Somatosensory deafferentation research with monkeys: implications for rehabilitation medicine. In: Ince LP, eds. Behavioral Psychology in Rehabilitation Medicine: Clinical Applications, New York, Williams \& Wilkins Co., 1980:371-401

10. Winstein CJ, Wolf SL, Dromerick AW et al. Effect of a task-oriented rehabilitation program on upper extremity recovery following motor stroke the ICARE randomized clinical trial. Jama. 2016;315(6):571-81.

11. Almhdawi, Khader. Effects of occupational therapy task-oriented approach in upper extremity post-stroke rehabilitation. Minnesota University. Dissertation of Docter's Degree. 2011.

12. DeLuca SC, Case-Smith J, Stevenson R et al. Constraint-induced movement therapy (CIMT) for young children with cerebral palsy: effects of therapeutic dosage. J Pediatr Rehabil Med. 2012;5(2):133-42.

13. Ko MS, Jeon HS, Kwon OY et al. The effects of modified constraint in duced therapy on upper extremity functions of children with hemipare- sis. Phys Ther Korea. 2005;12:81-9.

14. Yu EY. The effects of single and dual task balance training on stable and unstable surfaces on balance and walking ability in stroke patients. Yongin University. Dissertation of Master's Degree. 2016.

15. Jung JH. The effect of task-oriented movement therapy on upper extremity, upper extremity function and activities of daily living for stroke patients. Daegu University. Dissertation of Master's Degree. 2009.

16. Lee HS, Choi JH. Correlation between BBS, FRT, STI, TUG, MBI, and falling in stroke patients. J Kor Soc Phys Ther. 2008;20(4):1-6.

17. Jones EG, Powell TPS. An anatomical study of converging sensory pathways within the cerebral cortex of the monkey. Brain. 2016;93(4):793820 .

18. Martin K, Jacobs S, Frey SH. Handedness-dependent and independent cerebral asymmetries in the anterior intraparietal sulcus and ventral premotor cortex during grasp planning. Neuroimage. 2011;57(2):502-12.

19. Nudo RJ, Milliken GW, Jenkins WM et al. Use-dependent alterations of movement representations in primary motor cortex of adult squirrel monkeys. J Neurosci. 1996;16(2):785-807.

20. Park. RJ. Task oriented approach of hemiparetic patients. J Kor Soc Phys Ther. 2004;16(2):54-62.

21. Bosch J, Donnell MJ, Barreca S et al. Does task-oriented practice improve upper extremity motor recovery after stroke? a systematic review. ISRN Stroke. 2014:1-10.

22. Lowe A, Dorich J, Warnken B et al. Using virtual reality upper-extremity training combined with task practice to improve functional performance. AJOT. 2015;69(suppl 1):6911515055pl.

23. Kim SH, Park SH. The clinical art therapy program for concentration and cognitive development-based on action feedback. Society for Art Education of Korea. 2011;41:23-44.

24. Kohler, JM, Flanagan SP, Whiting WC. Muscle activation patterns while lifting stable and unstable loads on stable and unstable surfaces. J Strength Cond Res. 2010;24(2):313-21.

25. Tuna Z, Oska D, Onbulak D et al. Analysis of the effects of hospitalization on fine hand functions compared to gross grip in patients with rheumatoid arthritis. JCEI. 2015;6(3):228-32.

26. Chen YP, Pope S, Tyler D et al. Effectiveness of constraint-induced movement therapy on upper extremity function in children with cerebral palsy: a systematic review and meta-analysis of randomized controlled trials. Clin Rehabil. 2014;28(10):939-53.

27. Hwang BY, Kim JH, Chung SM. The effects of constraint-induced movement therapy on improvement of hand function in hemiplegic side. J Kor Soc Phys Ther. 2009;21(2):9-14.

28. Hoare BJ, Imms C, Carey L et al. Constraint-induced movement therapy in the treatment of the upper limb in children with hemiplegic cerebral palsy: a cochrane systematic review. Clin Rehabil. 2007;21:675-85.

29. Chiu HC, Ada L. Constraint-induced movement therapy improves upper limb activity and participation in hemiplegic cerebral palsy: a systematic review. Journal of Physiotherapy. 2016;62(3):130-7.

30. Taub E, Ramey SL, DeLuca SC et al. Efficacy of constraint-induced movement therapy for children with cerebral palsy with asymmetric motor impairment. Pediatrics. 2004;113(2):305-12.

31. Oskoui M, Coutinho F, Dykeman J et al. An update on the prevalence of cerebral palsy: a systematic review and meta-analysis. Dev Med Child Neurol. 2013;55(6):509-19. 
32. Lee WJ, Kong YS, Ko YM et al. Effect of unstable surface exercise on trunk posture and balance ability in patients with scoliosis: after six months follow-up. J Korean Soc Phys Ther. 2013;25(5):232-8.

33. Kim SJ, Jong HW, Oh JS et al. Comparison of abdominal oblique muscle activity during leg raising in hook-lying position according to surface conditions. Phys Ther Korea. 2006;13(3):102-10.

34. Yoo JS, Jeong JR, Lee WH. The effect of trunk stabilization exercise using an unstable surface on the abdominal muscle structure and balance of stroke patients. J Phys Ther Sci. 2014;26(6):857-9.

35. Shin JW, Song GB. The effects of neck and trunk stabilization exercises on upper limb and visuoperceptual function in children with cerebral palsy. J Phys Ther Sci. 2016;28(11):3232-5.

36. Jang SH, Ann JH, Kim JS. Effect of trunk control training on labile surface on relative impulse in the persons with stroke. J Kor Soc Phys Ther. 2012;24(2):163-9. 